\title{
Transient Receptor Potential Vanilloid Type I Channel May Modulate Opioid Reward
}

\author{
Thi-Lien Nguyen 1,3, Seung-Hwan Kwon',3, Sa-lk Hong',3, Shi-Xun Ma', Yang-Hee Jung', Ji-Young Hwang', \\ Hyoung-Chun Kim ${ }^{2}$, Seok-Yong Lee' and Choon-Gon Jang*,' \\ 'Department of Pharmacology, School of Pharmacy, Sungkyunkwan University, Suwon, Republic of Korea; ${ }^{2}$ Neurotoxicology Program, \\ College of Pharmacy, Korea Institute of Drug Abuse, Kangwon National University, Chuncheon, Republic of Korea
}

\begin{abstract}
Transient receptor potential vanilloid type I (TRPVI), a nonselective cation channel, is a well-known pain-related receptor. TRPV I involvement in morphine-induced antinociception, tolerance, and withdrawal symptoms has been previously reported. Emerging evidence indicates that TRPVI may be related to both the cellular and behavioral effects of addictive drugs. In the present study, we investigated the role of TRPVI in morphine reward using the conditioned place preference (CPP) paradigm in mice. Repeated morphine treatments upregulated TRPVI expression in the dorsal striatum (DSt). Treatment with a TRPVI agonist potentiated morphine reward, and pretreatment with TRPVI antagonists attenuated these effects. Microinjection of a selective TRPVI antagonist into the DSt significantly inhibited morphine-CPP. In addition, treatment with a TRPVI antagonist suppressed morphine-induced increases in $\mu$-opioid receptor binding, adenylyl cyclase I (ACI), p38 mitogen-activated protein kinase (p38 MAPK), and nuclear factor kappa B (NF- $\kappa$ B) expression in the DSt. Administering a p38 inhibitor not only prevented morphine-CPP, but also prevented morphine-induced NF- $\kappa \mathrm{B}$ and TRPVI activation in the DSt. Furthermore, injecting an NF- $\kappa$ B inhibitor significantly blocked morphine-CPP. Our findings suggest that TRPVI in the DSt contribute to morphine reward via ACI, P38 MAPK, and NF- $\kappa$ B. Brain TRPVI may serve as a novel therapeutic target to treat morphine-addictive disorders.

Neuropsychopharmacology (20I4) 39, 24I4-2422; doi:I0.1038/npp.20I4.90; published online 2I May 20I4
\end{abstract}

\section{INTRODUCTION}

The opiate drug morphine has a long history of use both for medical and recreational purposes. Even though intense efforts have been focused on the issue for several centuries, it remains difficult to separate the therapeutic effects of the drug from its adverse side effects. One of the major drawbacks of repeated opiate use is the development of drug addiction because of the powerful rewarding properties of opiates. Drug addiction is a disorder characterized by compulsive drug consumption despite adverse health, economic, and social consequences, and is plagued by chronic relapse (Koob and Volkow, 2010). Even though the exact molecular and cellular mechanisms underlying morphine addiction are not yet fully understood, it is thought that long-term neural adaptations in specific brain reward regions have a crucial role (Nestler and Aghajanian, 1997). Repeated morphine exposure alters gene expression and subsequently induces stable changes in protein components (Ammon-Treiber and Hollt, 2005). There is

*Correspondence: Dr C-G Jang, Department of Pharmacology, School of Pharmacy, Sungkyunkwan University, 2066 Seobu-ro, Jangan-gu, Suwon 440-746, Republic of Korea, Tel: +82 31 290 7780, Fax: +82 31292 8800, E-mail: jang@skku.edu

${ }^{3}$ These authors contributed equally to this work.

Received II April 2013; revised 2I March 2014; accepted 8 April 2014; accepted article preview online 15 April 2014 mounting evidence suggesting that the alteration of protein profiles in the brain after repeated morphine exposure underlie morphine addiction (Bierczynska-Krzysik et al, 2006; Kim et al, 2005; Li et al, 2006a). Numerous proteins that change their expression pattern following morphine treatment are listed in these publications, but particular candidate proteins for morphine reward-related proteins have not been evaluated. The development of effective treatment for morphine addiction requires identifying a specific protein that has a key role in morphine-rewarding effects.

Transient receptor potential vanilloid type 1 (TRPV1) is a nonselective cation channel activated by endogenous lipids, capsaicin, heat, and low $\mathrm{pH}$ (Tominaga et al, 1998). Although TRPV1 expression in the brain is well documented (Cristino et al, 2006; Starowicz et al, 2008; Toth et al, 2005), its roles in health and disease are just beginning to be explored. Genetic association studies have revealed that the TRPV1 gene is involved in cannabinoid-addictive disorders (Agrawal and Lynskey, 2009). Growing evidence suggests that TRPV1 may be involved in the neuronal and behavioral adaptations induced by addictive drugs such as drug consumption, drug seeking, anxiety, and depression. Deleting the TRPV1 gene in mice can alter ethanol consumption (Blednov and Harris, 2009) and diminish anxiety and conditioned fear (Marsch et al, 2007); blocking TRPV1 also suppresses cocaine-seeking behavior in the reinstatement phase (Adamczyk et al, 2012). Intraprefrontal 
cortex or intraperitoneal (i.p.) administration of TRPV1 antagonist induces anxiolytic-like effects (Aguiar et al, 2009; Kasckow et al, 2004), and in preclinical models of depression-like behaviors induced by nicotine or immobilization stress, TRPV1 agonists show antidepressant-like effects in both the forced swimming and tail suspension tests (Hayase, 2011). Moreover, upregulation of TRPV1 in the dorsal root ganglion, spinal cord, and sciatic nerve through mitogen-activated protein kinase pathways after chronic morphine treatment contributed to morphine tolerance in rats (Chen et al, 2008). Recently, we reported that blocking TRPV1 with a TRPV1 antagonist, capsazepine, attenuated morphine tolerance and withdrawal symptoms in mice (Nguyen et al, 2010). Taken together, these data imply that TRPV1 may be a molecular target in morphine reward.

In the present study, we therefore sought to determine whether TRPV1 expression in the brain is altered by repeated morphine administration, and to assess the role of TRPV1 in morphine reward in mice. Furthermore, we studied possible mechanisms to explain how TRPV1 contributes to morphine reward.

\section{MATERIALS AND METHODS}

\section{Animals}

Four-week-old male Institute for Cancer Research mice (ICR (CD1) mice, 22-25 g, Dae Han Biolink, Eumseong, Korea) were used in the present study. Mice were acclimatized in an animal room under a 12-h light/dark cycle at $22 \pm 2{ }^{\circ} \mathrm{C}$ and fed ad libitum. All animal care procedures were conducted in accordance with the US National Institutes of Health Guide for the Care and Use of Laboratory Animals, and the study protocol was approved by the Institutional Animal Care and Use Committee of Sungkyunkwan University.

\section{Chemicals}

Morphine hydrochloride (Macfarlan Smith, Edinburgh, UK) and pyrollidine dithiocarbamate (PDTC; Sigma-Aldrich, St Louis, MO, USA) were dissolved in physiological saline. Capsazepine, capsaicin, SB203580 hydrochloride, and SB366791 (Tocris Cookson, Bristol, UK) were dissolved in physiological saline containing $10 \%$ dimethyl sulfoxide and 10\% Tween 80 (Sigma-Aldrich).

\section{Guide Cannula Implantation and IntraDorsal Striatum Microinfusion}

Mice were anesthetized with pentobarbital $(50 \mathrm{mg} / \mathrm{kg}$, i.p.) and a guide cannula ( $9 \mathrm{~mm}, 24$ gauge) was implanted laterally into the dorsal striatum (DSt). The coordinates were as follows: $+0.86 \mathrm{~mm} \mathrm{~A} / \mathrm{P},+1.5 \mathrm{~mm} \mathrm{M} / \mathrm{L}$, and $-2.7 \mathrm{~mm} \mathrm{D} / \mathrm{V}$ according to the atlas of Paxinos and Franklin (2004). Infusions were performed at a rate of $1 \mu \mathrm{l} / \mathrm{min} /$ site for $1 \mathrm{~min}$.

\section{Conditioned Place Preference Procedure}

Conditioned place preference (CPP) was performed in an apparatus consisting of two plexiglass compartments $(15 \times$ $15 \times 15 \mathrm{~cm})$ : one white with a textured floor and one black with a smooth floor. In the preconditioning phase, mice were habituated in the apparatus (day 1) and the displacement of the mice was recorded for $20 \mathrm{~min}$ on day 2 . In the conditioning phase (days 3-10), mice were confined to the less preferred compartment for $60 \mathrm{~min}$ after morphine injection $(5 \mathrm{mg} / \mathrm{kg}$, subcutaneously (s.c.)) on days $3,5,7$, and 9 , or to the preferred compartment after saline injection on days $4,6,8$, and 10 . During the post-conditioning phase (day 11), the time that the mice spent in each compartment was recorded for $20 \mathrm{~min}$. CPP scores were expressed as the differences between the pretesting and post-testing times that the mice spent in the drug-paired compartment.

On day 11, after finishing the behavior test, 6-week-old mice were killed by decapitation. Mouse brains were carefully removed, frozen in dry ice, and stored at $-80{ }^{\circ} \mathrm{C}$ for further study, including autoradiography, real-time RT-PCR, and western blot.

\section{Quantitative Receptor Autoradiography}

Tissue preparation. Mouse brains were cut into $20-\mu \mathrm{m}$ coronal sections at $-19{ }^{\circ} \mathrm{C}$ using a cryostat (Leica, Wetzlar, Germany). Sections were immediately mounted on $1.5 \%$ gelatin-coated slides (Fisher Scientific, PA, USA) and stored at $-80{ }^{\circ} \mathrm{C}$ until use.

TRPV1 receptor binding. Brain sections were incubated in assay buffer containing $1 \mathrm{nM}\left[{ }^{3} \mathrm{H}\right]$ resiniferatoxin $(38.31 \mathrm{Ci} /$ mmol, PerkinElmer, Boston, MA, USA) for $60 \mathrm{~min}$ at room temperature. Nonspecific binding was controlled by adding $1 \mu \mathrm{M}$-unlabeled resiniferatoxin to a parallel series of sections. The sections were allowed to air dry and were exposed to Kodak BioMax MR Film (Eastman Kodak, Rochester, NY, USA) along with $\left[{ }^{3} \mathrm{H}\right]$ autoradiographic microscales (Amersham Biosciences, NJ, USA) at $4{ }^{\circ} \mathrm{C}$ for 6 weeks.

$\mu$-Opioid receptor binding. Brain sections were incubated in buffer containing $4 \mathrm{nM}\left[{ }^{3} \mathrm{H}\right] \mathrm{DAMGO} \quad(56.8 \mathrm{Ci} / \mathrm{mmol}$, PerkinElmer) at room temperature for $60 \mathrm{~min}$. Slides were exposed to Kodak BioMax MR film (Eastman Kodak) along with $\left[{ }^{3} \mathrm{H}\right]$ autoradiographic microscales (Amersham Biosciences) at $4{ }^{\circ} \mathrm{C}$ for 3 weeks.

Autoradiography films were developed and quantified using Molecular Dynamic Image Quant software version 3.3.

\section{Real-Time RT-PCR}

Tissue preparation. Coronal brain sections (Bregma +1.7 to $+0.74 \mathrm{~mm}$ ) according to the mouse brain atlas (Paxinos and Franklin, 2004) were collected. The DSt regions were punched bilaterally using a Harris Uni-Core 1.20 (Ted Pella, Redding, CA, USA). These brain tissues were used for real-time RT-PCR and western blot assays.

Real-time RT-PCR. Total RNA was isolated from brain tissues using the RNeasy microkit (Qiagen, Valencia, CA, USA) and quantified spectrophotometrically. Real-time PR-PCR was performed using an Invitrogen kit with TRPV1 primers (forward: 5'-AGCCATGCTCAATCTGCA C- $3^{\prime}$ and reverse: $5^{\prime}$-TGCTGTCTGGCCCTTGTAG-3'); and $\beta$-actin primers (forward: $5^{\prime}$-AGAGGGAAATCGTGCGTGAC$3^{\prime}$ and reverse: $5^{\prime}$-CAATAGTGATGACCTGGCCT- $3^{\prime}$ ). The 
comparative critical threshold, $\Delta \Delta C_{\mathrm{t}}$, was calculated using Corbett Research software version 1.7.75. The relative TRPV1 mRNA expression of each sample was the mean of triplicate measurements.

\section{Western Blot}

Tissues were homogenized and then were centrifuged for $20 \mathrm{~min}$ at 15000 r.p.m. at $4{ }^{\circ} \mathrm{C}$ to collect the supernatant. Supernatants $(50 \mu \mathrm{g})$ were separated by $6 \%$ SDS-PAGE and transferred to polyvinylidene fluoride membranes. Membranes were incubated with primary antibodies and then with secondary antibodies. Binding sites were visualized on Kodak BioMax MR Film (Eastman Kodak) using a Western Lightning Detection Kit (PerkinElmer Life Science). Specific bands were quantified by densitometric analysis using Image Gauge software version 4.0. Data were calculated as a relative ratio to the control.

\section{Immunohistochemistry}

Tissue preparation. After CPP, mice were intracardially perfused with a solution containing $4 \%$ paraformaldehyde. Brains were post fixed in $4 \%$ paraformaldehyde and then placed in 30\% sucrose, after which they were frozen and sectioned coronally at $40 \mu \mathrm{m}$ using a cryostat (Leica).

Immunohistochemistry. Brain sections were incubated with the primary antibodies. For immunoperoxidase staining, biotinylated secondary antibody $(7 \mu \mathrm{g} / \mathrm{ml}$; Vector Laboratories) was applied, followed by incubation with an avidin-biotin horseradish peroxidase complex (Vector Laboratories). The peroxidase label was detected by incubating in $3,3^{\prime}-4,4^{\prime}$-diaminobenzidine (Sigma). For double-fluorescent staining, a mixture of Alexa Fluor 488 anti-rabbit and Alexa Fluor 568 anti-guinea pig IgG antibodies (1:1000; Molecular Probes) was applied. Images were taken using a DP digital microscope camera (Olympus Optical, Tokyo, Japan) connected to a microscope (BX 51, Olympus, Tokyo, Japan).

p-p38, pNF- $\kappa$ B (p-nuclear factor kappa B), and adenylyl cyclase type 1 and 8 (AC1 and AC8) IR cells were manually counted in a fixed box size of $150 \times 150 \mu \mathrm{m}^{2}$ in the center of the DSt by an observer blinded to the experimental groups. Data were represented as a relative ratio to the control (\%). Details on methods used in this study are provided in the Supplementary Information.

\section{Statistical Analyses}

The data were expressed as mean \pm SEM. The experimental data were analyzed by one-way analysis of variance followed by the Newman-Keuls post hoc test or Student's $t$-test using Prism version 5.0 (Graph Pad Software). A value of $P<0.05$ was considered statistically significant.

\section{RESULTS}

\section{Morphine-Upregulated TRPV1 Expression in the DSt}

In order to determine the effects of morphine on TRPV1 expression, we administrated morphine $(5 \mathrm{mg} / \mathrm{kg}$, s.c., every other day for 4 days) following the CPP schedule. Morphine treatment increased significantly the TRPV1 mRNA level in the DSt in the morphine group $(3.64 \pm 1.02$ vs $1.00 \pm 0.30$, $t(12)=2.47, P=0.029$; Figure $1 \mathrm{~b}$ ). In addition, TRPV1 protein levels in the DSt were also higher in the morphine group $(2.30 \pm 0.13$ vs $1.00 \pm 0.05, \quad t(4)=9.88, \quad P<0.001$; Figure $1 \mathrm{c}$ and $\mathrm{d})$. Moreover, $\left[{ }^{3} \mathrm{H}\right]$ resiniferatoxin binding in the DSt increased in the morphine group compared with the control group $(157.9 \pm 5.12$ vs $133.4 \pm 7.75 \mathrm{fmol} / \mathrm{mg}$ tissue, $t(24)=2.71, P=0.012$; Figure 1e and f).

\section{Effects of a TRPV1 Agonist and Antagonists and on Morphine-CPP}

On the conditioning days, mice were received i.p. injection of a TRPV1 agonist, capsaicin, or of TRPV1 antagonists 30 min before administering s.c. morphine. Pretreatment with TRPV1 antagonists significantly suppressed morphine-CPP. Capsazepine $(2.5 \mathrm{mg} / \mathrm{kg}$, i.p.) significantly reduced morphine$\mathrm{CPP} \quad(\mathrm{F}(4,47)=4.42, \quad P=0.004 ;$ post hoc test, $P<0.05$; Figure 2a). SB366791 pretreatment $(37.5,75$, and $150 \mu \mathrm{g} / \mathrm{kg}$, i.p.) reduced CPP scores in a dose-dependent manner compared with vehicle/morphine $(\mathrm{F}(5,64)=2.83, P=0.022)$. At $150 \mu \mathrm{g} / \mathrm{kg}$, SB366791 significantly blocked morphine-CPP (post hoc test, $P<0.05$; Figure $2 \mathrm{~b}$ ). In contrast, pretreatment with capsaicin significantly enhanced morphine-CPP $(\mathrm{F}(4,39)=4.33, P=0.033)$. Alone, a low dose of morphine $(1.5 \mathrm{mg} / \mathrm{kg}$, s.c.) did not significantly induce CPP. However, when co-treated with capsaicin $(200 \mu \mathrm{g} / \mathrm{kg}$, i.p.), low-dose morphine $(1.5 \mathrm{mg} / \mathrm{kg}$, s.c.) remarkably increased CPP score compared with vehicle (post hoc test, $P<0.01$ ) or morphine control (post hoc test, $P<0.05$, Figure $2 \mathrm{c}$ ).

To verify that the effects of capsaicin on morphine-CPP were mediated by TRPV1 receptor activation and not nonspecific activation of other receptors, we examined the effects of capsaicin on morphine-CPP in the presence of SB366791. First, SB366791 was injected, $15 \mathrm{~min}$ later capsaicin was injected. and $30 \mathrm{~min}$ later morphine was injected. As shown in Figure 2d, capsaicin $(200 \mu \mathrm{g} / \mathrm{kg}$, i.p.) significantly potentiated morphine-CPP compared with the vehicle or morphine control groups $\left(\mathrm{F}_{(4,58)}=3.82, P=0.008\right)$. These effects were antagonized by SB366791 (post hoc test, $P<0.05)$. Administration of capsaicin, capsazepine, and SB366791 did not produce any significant differences in CPP score compared with the vehicle control groups.

As systemic administration of a TRPV1 agonist and antagonists significantly affected the CPP score of morphine and repeated morphine treatment upregulated TRPV1 in the DSt, striatum TRPV1 may have a role in morphine reward. To validate this hypothesis, a selective TRPV1 antagonist, SB366791, was injected laterally into the DSt 30 min before morphine injection on each conditioning day. As shown in Figure 2e and f, SB366791 (0.2 ng/site) significantly attenuated morphine-induced $\mathrm{CPP}(\mathrm{F}(2,24)=5.84$, $P=0.009$; post hoc test, $P<0.05)$.

\section{Effects of a TRPV1 Antagonist on $\mu$-Opioid Receptor Binding in the DSt of Morphine-CPP Mice}

To examine whether TRPV1 antagonist affects the binding site of $\mu$-opioid receptors in the DSt, autoradiographic analysis was performed using $\left[{ }^{3} \mathrm{H}\right] \mathrm{DAMGO}$. Autoradiographic data showed that repeated morphine treatments significantly increased $\left[{ }^{3} \mathrm{H}\right] \mathrm{DAMGO}$ binding in the DSt $(\mathrm{F}(2,26)=5.37$, 

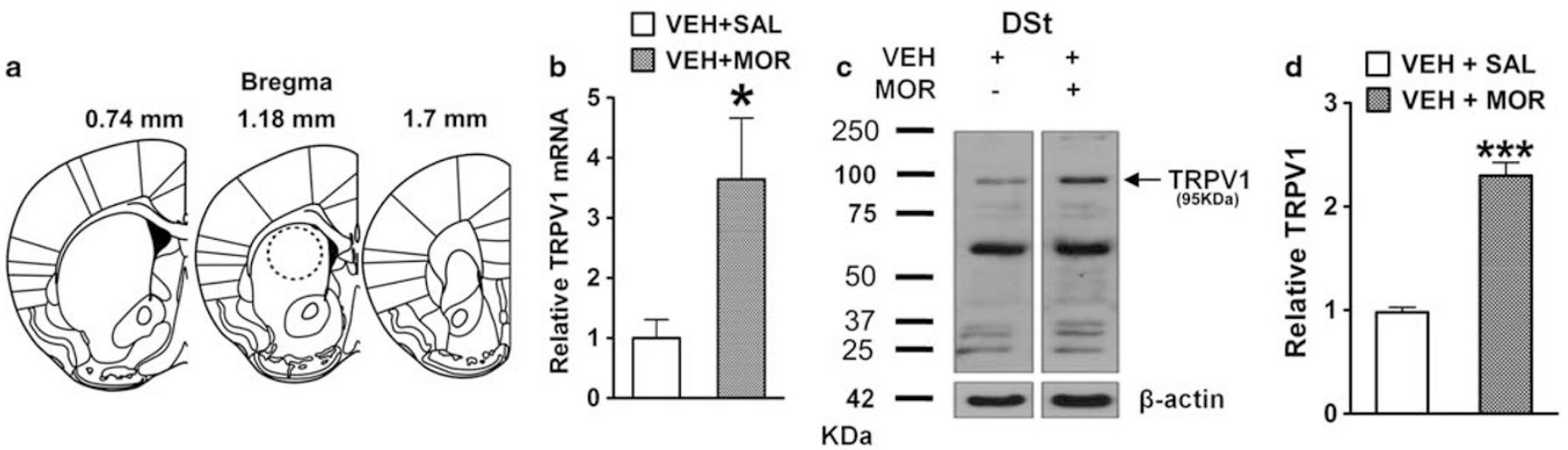

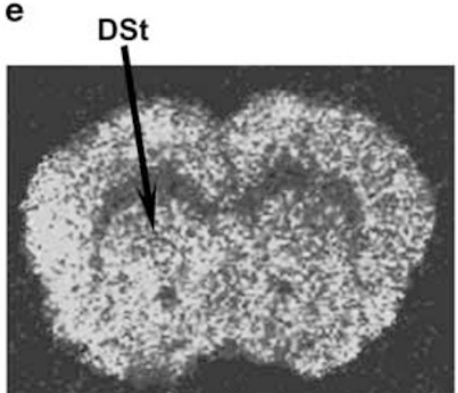

$\mathrm{VEH}+\mathrm{SAL}$

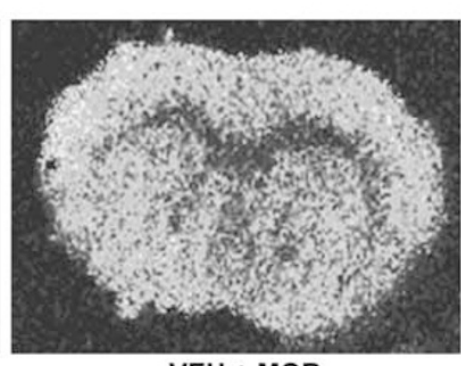

VEH + MOR

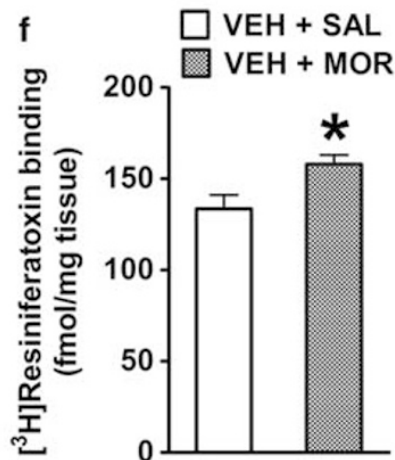

Figure I Morphine-upregulated transient receptor potential vanilloid type I (TRPVI) expression in the dorsal striatum (DSt). (a) The locations of punched samples. (b) Quantitative analysis of TRPVI mRNA levels ( $n=7 /$ group). (c, d) Representative images and quantitative analysis of TRPVI levels ( $n=3$ /group). (e, f) Representative autoradiograph and quantitative analysis of $\left[{ }^{3} \mathrm{H}\right]$ resiniferatoxin binding $(n=|2-| 4 /$ group). $* * * * P<0.00 \mid$, $* P<0.05$ vs the control group. MOR, morphine (5 mg/kg); SAL, saline; VEH, vehicle.

$P<0.011)$ of morphine-CPP mice compared with the vehicle control group (Figure 3 ). These increases were diminished by capsazepine pretreatment (post hoc test, $P<0.05$ ).

\section{A TRPV1 Antagonist Suppresses Morphine-Induced Increases in AC1 Expression in the DSt}

Superactivation of $\mathrm{AC} 1$ and $\mathrm{AC} 8$ is known to have a role in morphine dependence (AC1 and AC8) (Lane-Ladd et al, 1997). Knocking out both $A C 1$ and $A C 8$ genes significantly reduces morphine- $\mathrm{CPP}$, suggesting that $\mathrm{ACl}$ and/or $\mathrm{AC} 8$ are necessary for morphine-CPP (Li et al, 2006b). Thus, we determined levels of $\mathrm{AC} 1$ and AC8 in CPP samples treated with SB366791. Immunohistochemistry data revealed that the number of AC1 IR cells was increased in the DSt $(\mathrm{F}(2,15)=12.56, P<0.001)$ of morphine-CPP mice (Figure 4a and b). Pretreatment with SB366791 significantly blocked morphine-induced increases in $\mathrm{ACl}$ in the $\mathrm{DSt}$ (post hoc test, $P<0.01$; Figure $4 \mathrm{a}$ and $\mathrm{b}$ ). There were no significant changes in the number of AC8 IR cells in the DSt $(\mathrm{F}(2,15)=0.67$, NS; Figure 4c) among the saline, morphine, and SB366791-morphine groups. Western blot data also indicated that SB366791 significantly reduced morphineinduced increases in $\mathrm{ACl}$ in the DSt $(\mathrm{F}(2,6)=111.2$, $P<0.001$; post hoc test $P<0.01$; Figure $4 \mathrm{~d}$ and e).

\section{TRPV1 Antagonists Suppress Morphine-Activated $\mathrm{p} 38 / \mathrm{NF}-\kappa \mathrm{B}$ in the DSt}

Previously, it was reported that the $\mathrm{p} 38 / \mathrm{NF}-\kappa \mathrm{B}$ pathway is involved in morphine reward in rats (Zhang et al, 2011). To verify this finding, we studied the effects of p38 inhibitor SB203580 and NF- $\kappa$ B inhibitor PDTC in morphine-CPP in mice. The CPP data revealed that SB203580 (0.125, 0.25 , and $0.5 \mathrm{mg} / \mathrm{kg}$, i.p.) prevented morphine-CPP in a dose-dependent manner $\left(\mathrm{F}_{(5,67)}=3.85, \quad P=0.004\right)$. At $0.5 \mathrm{mg} / \mathrm{kg}$, SB203580 significantly blocked morphine-CPP (post hoc test, $P<0.05$; Figure 5e). No significant difference in CPP scores was detected between the SB203580-saline and vehicle-saline groups. Similarly, PDTC $(5,25$, and $50 \mathrm{mg} / \mathrm{kg}$, i.p.) prevented morphine-CPP in a dosedependent manner $\left(F_{(5,53)}=3.24, P=0.013\right.$; Figure $\left.5 j\right)$. At $50 \mathrm{mg} / \mathrm{kg}$, PDTC significantly blocked morphine-CPP (post hoc test, $P<0.05$ ). No significant difference in CPP scores was detected between the PDTC-saline and salinesaline groups. Our data suggest that $\mathrm{p} 38$ and NF- $\kappa \mathrm{B}$ activation are necessary for morphine reward in mice.

To investigate whether the effects of TRPV1 antagonist SB366791 on morphine reward are related to p38 and NF$\kappa \mathrm{B}$, the levels of p-p38 and pNF- $\kappa \mathrm{B}$ were assessed in CPP samples treated with SB366791. The number of cells expressing p-p38 (Figure $5 \mathrm{a}$ and $\mathrm{b}$ ) and $\mathrm{pNF}-\mathrm{kB}$ (Figure $5 \mathrm{f}$ and $\mathrm{g}$ ) in the DSt increased significantly in the morphine control group $\left(\mathrm{F}_{(2,15)}=5.33, P=0.018\right.$; and $\mathrm{F}_{(3,20)}=5.91$, $P=0.005$, respectively). These increases were attenuated by SB366791 (post hoc test, $P<0.05$ and $P<0.05$, respectively). Consistent with immunohistochemistry data, western blot data indicated that SB366791 treatment significantly decreased morphine-induced increases in p-p38 $(\mathrm{F}(2,6)=$ $110.0, P<0.001$; post hoc test $P<0.001$; Figure $5 \mathrm{c}$ and $\mathrm{d}$ ) and pNF- $\kappa \mathrm{B} \quad(\mathrm{F}(3,8)=316.3, P<0.001$; post hoc test, $P<0.001$; Figure $5 \mathrm{~h}$ and i) in the DSt. In addition, a p38 inhibitor, 

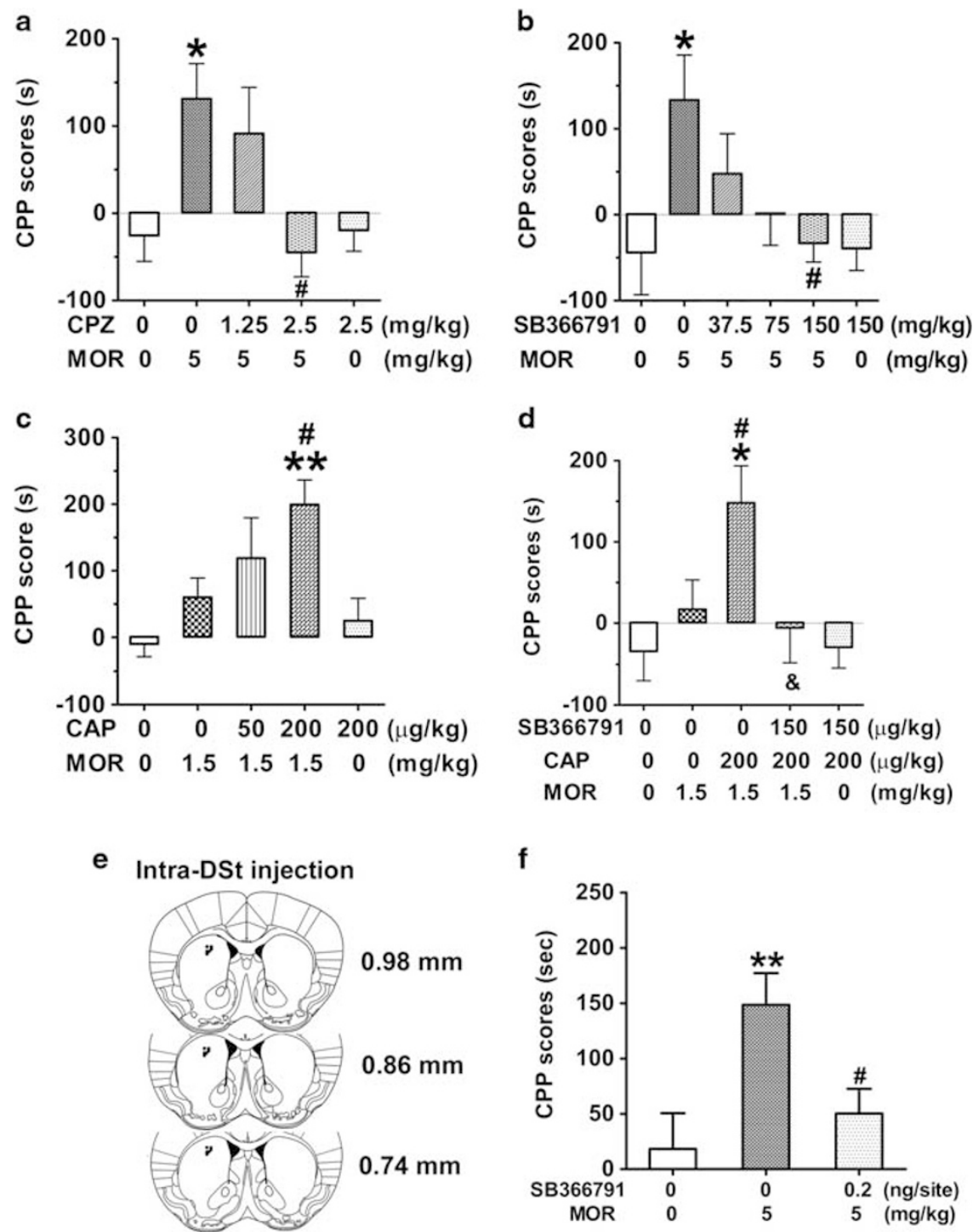

Figure 2 Effects of a transient receptor potential vanilloid type I (TRPVI) agonist and antagonists on morphine-conditioned place preference (CPP). Capsazepine (a) and SB36679I (b) prevented morphine-CPP in mice (*P $<0.05$ vs VEH + SAL; ${ }^{*} P<0.05$ vs VEH + MOR). (c) Capsaicin-enhanced morphine-CPP in mice (**P $<0.01$ vs VEH + SAL; ${ }^{*} P<0.05$ vs VEH + MOR). (d) SB36679I antagonizes the effects of capsaicin on morphine-CPP in mice ( ${ }^{*} P<0.05$ vs $\mathrm{VEH}+\mathrm{VEH}+\mathrm{SAL}$; ${ }^{\#} P<0.05$ vs $\mathrm{VEH}+\mathrm{VEH}+\mathrm{MOR}$; ${ }^{\&} \mathrm{P}<0.05$ vs $\left.\mathrm{VEH}+\mathrm{CAP}+\mathrm{MOR}\right)$. (e) The location of microinjection into the dorsal striatum (DSt). (f) Microinjection of a TRPVI antagonist into the DSt significantly prevented morphine-CPP. $n=8-\mid 3 / g r o u p . * * P<0.0$ I vs VEH + SAL; ${ }^{\#} P<0.05$ vs VEH + MOR. CAP, capsaicin; CPZ, capsazepine; MOR, morphine; SAL, saline; VEH, vehicle.

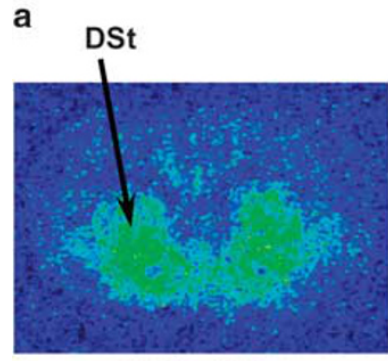

$\mathrm{VEH}+\mathrm{SAL}$

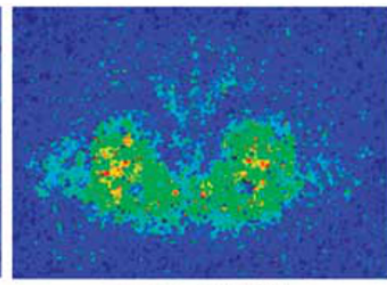

VEH + MOR

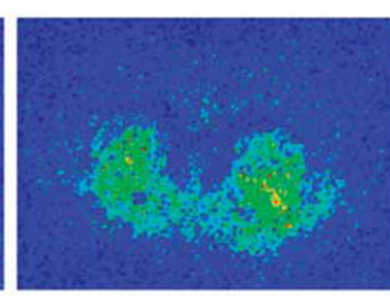

$\mathrm{CPZ}+\mathrm{MOR}$

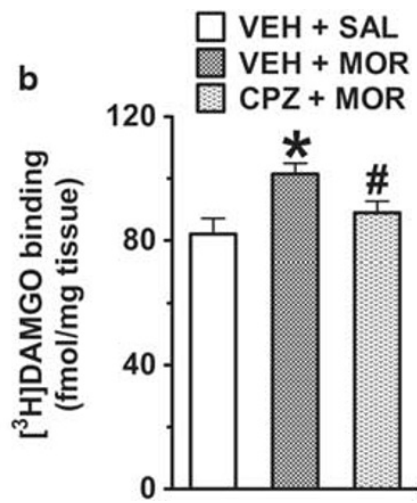

Figure 3 The effects of a transient receptor potential vanilloid type I (TRPVI) antagonist on ${ }^{3}$ HIDAMGO binding in the dorsal striatum (DSt) of morphineconditioned place preference (CPP) mice. Representative autoradiogram (a) and quantitative analysis (b) of $\left.{ }^{3} \mathrm{H}\right] \mathrm{DAMGO}$ binding in mouse brains ( $n=9-\mathrm{I0} /$ group). *P<0.05 vs VEH + SAL; ${ }^{\#} P<0.05$ vs VEH + MOR. CPZ, capsazepine (2.5 mg/kg); MOR, morphine (5 mg/kg); SAL, saline; VEH, vehicle. 
a

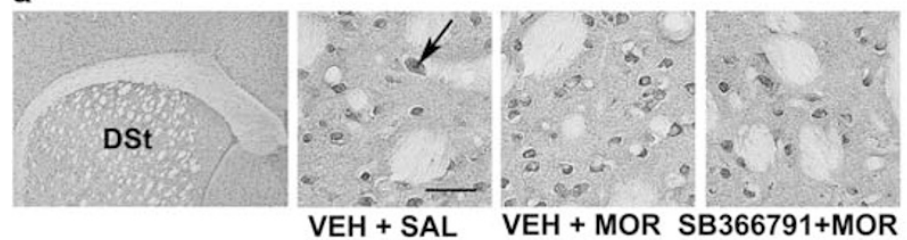

b

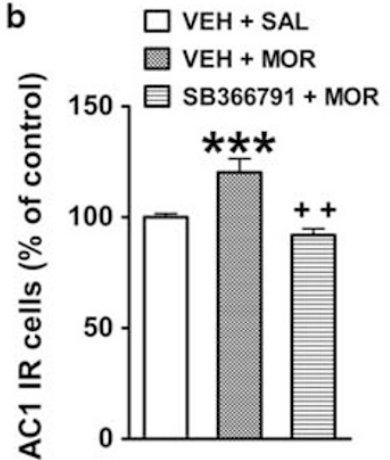

d

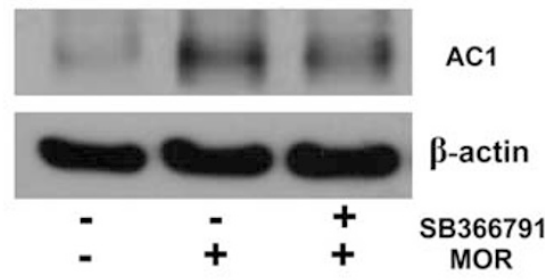

e

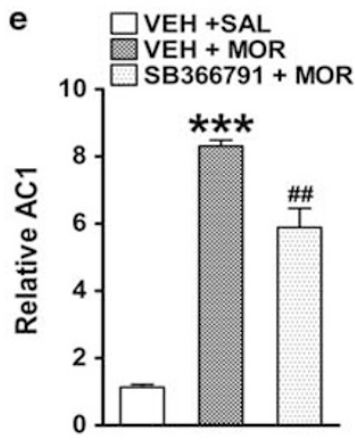

Figure 4 Effects of a transient receptor potential vanilloid type I (TRPVI) antagonist on adenylyl cyclase type I and 8 (ACI and AC8) expression. (a) Photomicrographs of $A C I I R$ cells in the dorsal striatum (DSt). The arrow indicates an ACI IR cell; scale bars, $40 \mu \mathrm{m}$. (b, c) Quantitative analysis of the number of $\mathrm{ACl}$ and $\mathrm{AC} 8 \mathrm{IR}$ cells $\left(n=6 /\right.$ group). $* * * * P<0.001$ vs VEH $+\mathrm{SAL} ;{ }^{+}+P<0.01$ vs VEH $+\mathrm{MOR}$. (d, e) Representative images and quantitative

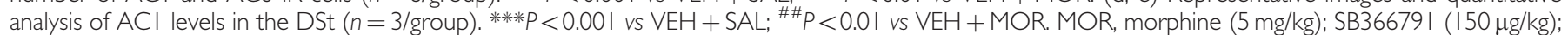
SAL, saline; VEH, vehicle.

SB203580, diminished the increase of $\mathrm{pNF}-\kappa \mathrm{B}$ in the DSt (post hoc test, $P<0.01$; Figures $5 f$ and $g$ and $P<0.001$; Figure $5 \mathrm{~h}$ and $\mathrm{i}$ ), confirming that $\mathrm{p} 38$ functions upstream of $\mathrm{NF}-\kappa \mathrm{B}$ in a signaling cascade involved in morphine reward.

\section{DISCUSSION}

In the present study, we found that repeated morphine administration upregulated TRPV1 expression in the DSt, having a role in morphine reward. Our data are consistent with the results of previous studies, which have reported that TRPV1 is widely expressed and functions in many brain structures including the DSt (Cristino et al, 2006; Maccarrone et al, 2008). However, a recent study suggested that TRPV1 expression was limited to the caudal hypothalamus and adjacent areas (Cavanaugh et al, 2011). In that study, TRPV1 expression was examined using reporter sequences inserted into the final exon of the TRPV1 gene. However, their methods did not account for the possibility of TRPV1 isoforms, such as splice variants, that do not include the final exon. In addition, the internal ribosome entry site in the reporter sequence may have been incompatible with certain brain cells, leading to false negatives. We used multiple techniques, namely RT-PCR, western blot analysis, and autoradiographic binding, to accurately confirm the presence of TRPV1 in the DSt.

Two previous studies have demonstrated that TRPV1 has a role in synaptic transmission and neuroplasticity in the striatum (Grueter et al, 2010; Maccarrone et al, 2008). TRPV1 is functional in synaptic structures and participates in forming neural networks and regulating vesicle recycling (Goswami et al, 2010). As a synaptic protein with a role in neuroplasticity, upregulation of TRPV1 in the DSt may modify synaptic functions and significantly contribute to morphine reward. Indeed, our behavioral data confirmed the critical contribution of TRPV1 in morphine reward. Blocking TRPV1 with different selective antagonists significantly suppressed morphine-CPP. In contrast, activation of TRPV1 with a selective agonist potentiated morphineCPP. In addition, pretreatment with a TRPV1 antagonist reversed the effects of the TRPV1 agonist on morphineCPP, confirming that the effects of TRPV1 antagonists and agonist on morphine-CPP were because of selective effects on TRPV1 and not off-target effects. As capsaicin by itself did not induce CPP, TRPV1 activation is necessary but not sufficient for morphine reward. Furthermore, local microinjection of a selective TRPV1 antagonist into the DSt blocked morphine-CPP, indicating that DSt TRPV1 significantly contributed to morphine reward. The DSt, a component of the nigrostriatal dopamine pathway, was reported to be involved in reward-based learning (Balleine et al, 2007; Schmitzer-Torbert and Redish, 2004) and drug seeking (Vanderschuren et al, 2005). Electrolytic lesions of either the DStor ventral striatum significantly reduced morphine self-administration, suggesting that these regions have critical roles in the rewarding properties of morphine (Suto et al, 2011). As our study only focused on TRPV1 in the DSt, we could not rule out the role of TRPV1 in other brain regions such as the cortex, nucleus accumbens, and ventral tegmental area, which may also participate in morphine reward. These hypotheses will be explored in future studies.

Although the in vivo mechanisms of morphine-modulated TRPV1 function remain unclear, studies have demonstrated that morphine modulates TRPV1 function in vitro through a cAMP-dependent protein kinase A (PKA) pathway (Vetter et al, 2006). Chronic morphine treatment 

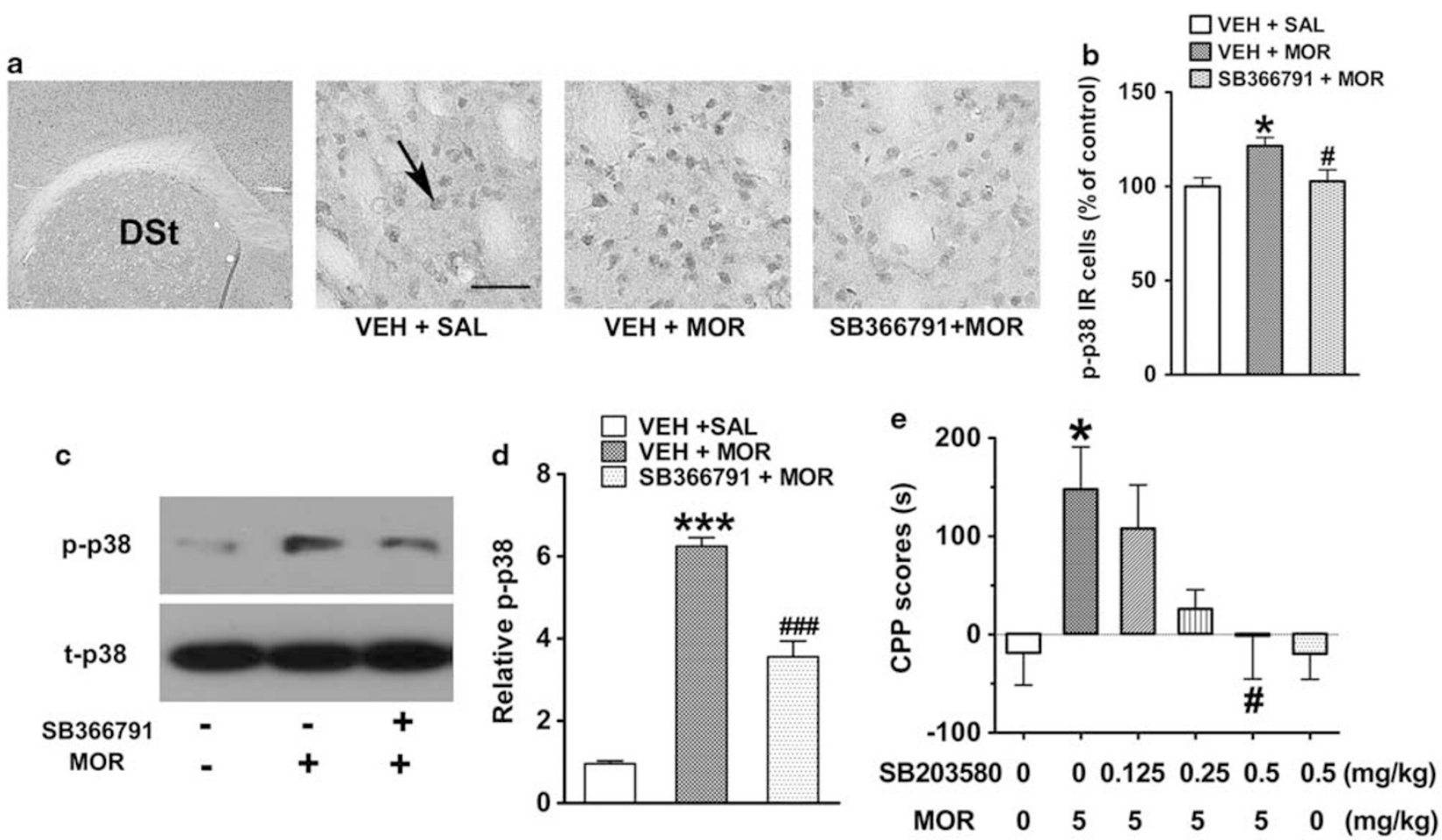

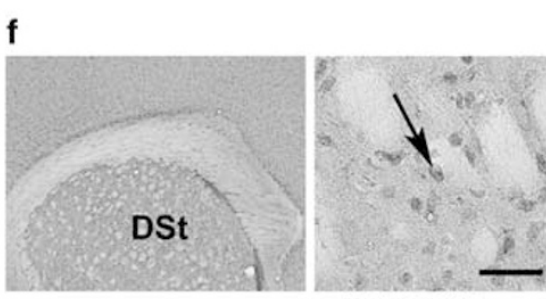

$\mathrm{VEH}+\mathrm{SAL}$

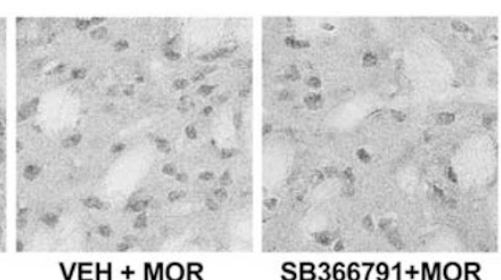

VEH + MOR
SB366791+MOR

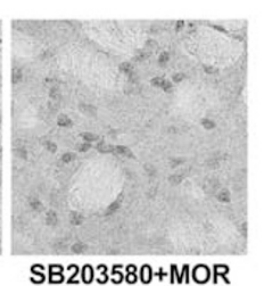

SB203580+MOR
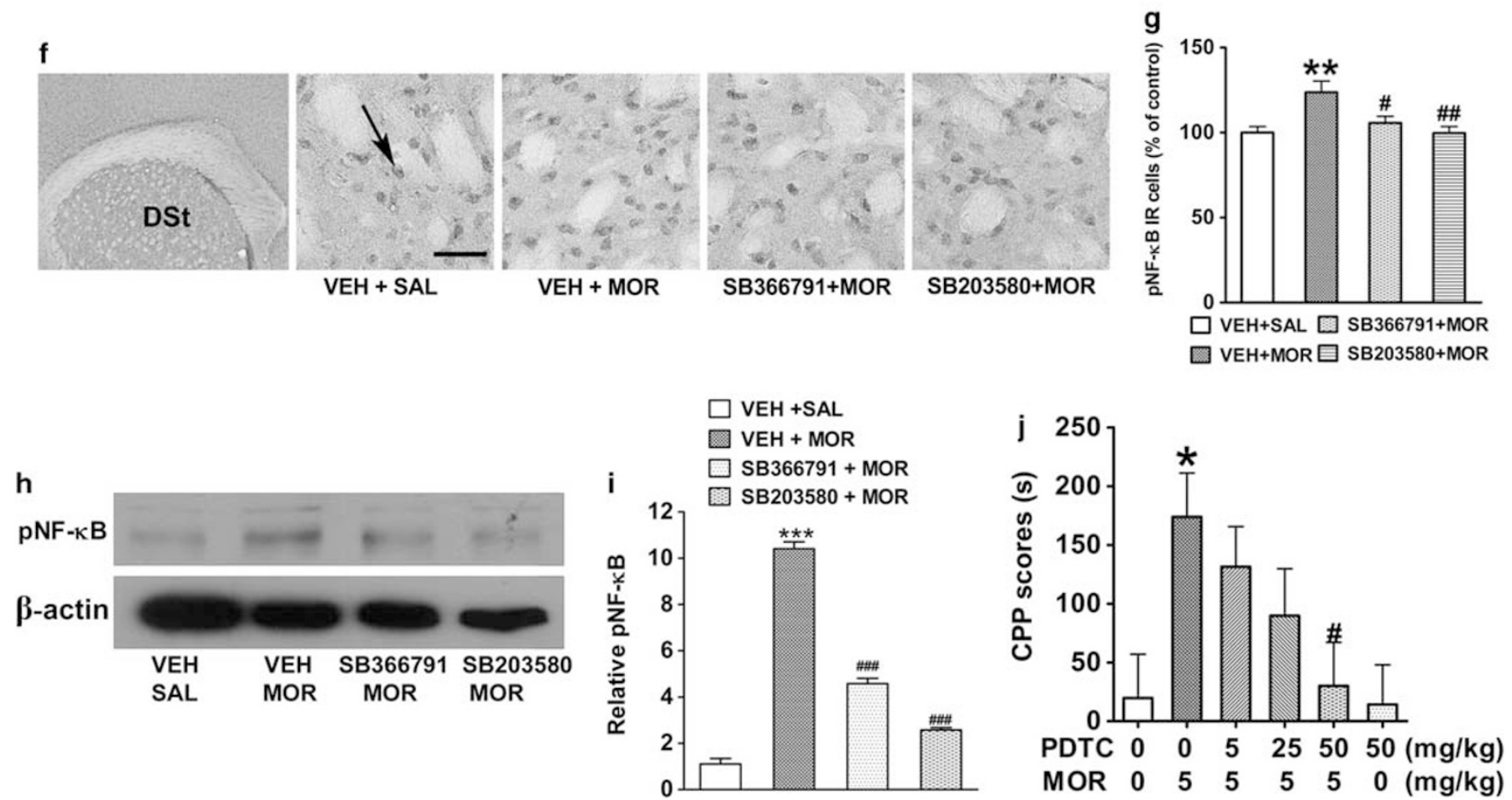

Figure 5 Effects of a transient receptor potential vanilloid type I (TRPVI) antagonist on p38/nuclear factor kappa B (NF- $\kappa$ B) in the dorsal striatum (DSt) of morphine-conditioned place preference (CPP) mice. (a, b) Photomicrographs and quantitative analysis of the number of $p-p 38$ IR cells ( $n=6 / g r o u p)$. (c, d) Representative images and quantitative analysis of p-p38 levels in the DSt ( $n=3 /$ group). (e) Effects of a selective p-p38 inhibitor on morphine-CPP in mice ( $n=12-13$ /group). ( $f, g)$ Photomicrographs and quantitative analysis of the number of pNF- $k B$ IR cells $(n=6 / g r o u p)$. (h, i) Representative images and quantitative analysis of pNF- $\kappa$ B levels in the DSt ( $n=3 /$ group). (j) Effects of a selective pNF- $\kappa$ B antagonist on morphine-CPP in mice ( $n=9-10 /$ group).

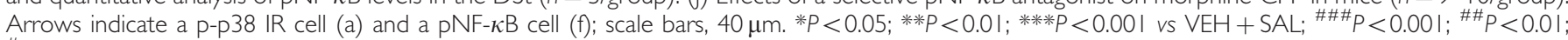
${ }^{\#} P<0.05$ vs VEH + MOR. MOR, morphine; SAL, saline; VEH, vehicle.

increased the activity of cAMP-dependent protein kinases such as PKA and PKC (Terwilliger et al, 1991). Activity of the TRPV1 channel was found to be modulated by PKA and
PKC (Tominaga et al, 1998); thus, morphine might modulate in vivo TRPV1 function through PKA, PKC, or both pathways. 
There are at least three possible mechanisms underlying the effects of TRPV1 antagonists on morphine reward. One possible mechanism is that TRPV1 affects $\mu$-opioid receptor binding, which is increased by morphine. Fattore et al (2007) demonstrated that $\left[{ }^{3} \mathrm{H}\right]$ DAMGO binding in the $\mathrm{CPu}$ was remarkably elevated in rats self-administering heroin compared with controls. Similarly, our data also indicated that $\left[{ }^{3} \mathrm{H}\right]$ DAMGO binding in the DSt increased significantly in mice with a preference for the morphine-paired compartment. The increased binding of $\mu$-opioid receptors was diminished by a TRPV1 antagonist.

The second possible mechanism is that a TRPV1 antagonist suppresses morphine-induced $\mathrm{AC} 1$ upregulation, thereby preventing the upregulation of the CAMP signaling. Upregulation of the cAMP pathway in the NAc reportedly contributes to morphine reward (Kelley and Holahan, 1997), and repeated morphine administration upregulates AC1 and AC8 (Lane-Ladd et al, 1997). Knocking out both the $A C 1$ and $A C 8$ genes significantly reduces morphine$\mathrm{CPP}$, suggesting that $\mathrm{AC} 1, \mathrm{AC} 8$, or both are necessary for morphine-CPP (Li et al, 2006b). Our data show that upregulation of $\mathrm{AC} 1$ but not $\mathrm{AC} 8$ in the $\mathrm{DSt}$ is involved in morphine-CPP. We could not rule out the involvement of other AC isoforms in morphine reward. $\mathrm{ACl}, \mathrm{a} \mathrm{Ca}^{2+}$ activated enzyme, is stimulated by low $\mathrm{Ca}^{2+}$ concentrations $(150-200 \mathrm{nM})$, and is approximately five times more sensitive to $\mathrm{Ca}^{2+}$ than AC8 (Nielsen et al, 1996). The TRPV1 channel is highly permeable to $\mathrm{Ca}^{2+}$, which is similar to the NMDA receptor channel, and thus TRPV1 can trigger $\mathrm{Ca}^{2+}$-mediated cell signaling (Kauer and Gibson, 2009). Simultaneous upregulation of the highly $\mathrm{Ca}^{2+}$. permeable TRPV1 channels and $\mathrm{Ca}^{2+}$-stimulated $\mathrm{ACl}$ in the DSt may be involved in morphine reward. Therefore, TRPV1 antagonists might inhibit morphine reward in two distinct ways such as (1) by blocking TRPV1 to reduce intracellular $\mathrm{Ca}^{2+}$ levels, which activates $\mathrm{ACl}$, and (2) by suppressing morphine-induced AC1 upregulation.

A third possible mechanism may be the blockade of morphine reward by the TRPV1 antagonist via the inhibition of $\mathrm{p} 38 / \mathrm{NF}-\kappa \mathrm{B}$ signaling. The $\mathrm{p} 38 / \mathrm{NF}-\kappa \mathrm{B}$ signaling pathway in the nucleus accumbens has a critical role in morphine reward in rats (Zhang et al, 2011). Similarly, our data showed that repeated morphine administration increases $\mathrm{p} 38$ and NF- $\kappa \mathrm{B}$ phosphorylation in the DSt of morphine-CPP mice. In addition, we found that a p38 inhibitor repressed morphine-induced increases in NF- $\kappa$ B phosphorylation, implicating $\mathrm{p} 38$ as an upstream regulator of NF- $\kappa \mathrm{B}$ in morphine reward. NF- $\kappa \mathrm{B}$ is a nuclear transcription factor and is reportedly regulated by p38 (Song et al, 2006). Phosphorylation of NF- $\kappa \mathrm{B}$ can enhance its DNA-binding ability and consequently alter target gene expression (Song et al, 2006), which may underlie the longterm neuroadaptive changes induced by morphine. Besides its role in immune and inflammatory responses, brain NF$\kappa \mathrm{B}$ was recently implicated in synaptic plasticity, learning, and memory (Meffert and Baltimore, 2005). Activation of p38 and NF- $\kappa$ B is required for reward-related learning and memory of drugs; in rats, inhibition of p38 blocked rewardrelated learning of methamphetamines (Gerdjikov et al, 2004), whereas a NF- $\kappa$ B inhibitor prevented reward-related memory of morphine (Yang et al, 2011). In present study, we found that a TRPV1 antagonist suppressed morphine- induced increases in phosphorylation of $\mathrm{p} 38$ and NF- $\kappa \mathrm{B}$ in the DSt. Taken together, our findings suggest that blockade of p38/NF- $\kappa$ B signaling in the DSt may underlie the effects of TRPV1 antagonists on morphine-CPP.

In conclusion, our data demonstrate that morphineinduced TRPV1 upregulation in the DSt significantly contributes to morphine reward. We also found that increased $\mu$-opioid receptor binding, $\mathrm{AC} 1$ upregulation, and $\mathrm{p} 38 / \mathrm{NF}-\kappa \mathrm{B}$ activation accompany morphine reward via TRPV1. The diagram in Supplementary Figure S1 illustrates the possible mechanism by which TRPV1 modulates morphine reward. TRPV1 might be a promising therapeutic target for treating morphine dependence.

\section{FUNDING AND DISCLOSURE}

The authors declare no conflict of interest.

\section{ACKNOWLEDGEMENTS}

This study was supported by the Korea Food and Drug Administration (14182KFDA979) and the Basic Science Research Program (NRF-2013R1A1A2062362 and MRC 2012R1A5A2A28671860), the National Research Foundation of Korea, Republic of Korea. We thank Professor Hyun Kim and Professor Ji Woong Choi for their technical assistance and helpful discussions.

\section{REFERENCES}

Adamczyk P, Miszkiel J, McCreary AC, Filip M, Papp M, Przegalinski E (2012). The effects of cannabinoid CB1, CB2 and vanilloid TRPV1 receptor antagonists on cocaine addictive behavior in rats. Brain Res 1444: 45-54.

Agrawal A, Lynskey MT (2009). Candidate genes for cannabis use disorders: findings, challenges and directions. Addiction 104: $518-532$.

Aguiar DC, Terzian AL, Guimaraes FS, Moreira FA (2009). Anxiolytic-like effects induced by blockade of transient receptor potential vanilloid type 1 (TRPV1) channels in the medial prefrontal cortex of rats. Psychopharmacology (Berl) 205: 217-225.

Ammon-Treiber S, Hollt V (2005). Morphine-induced changes of gene expression in the brain. Addict Biol 10: 81-89.

Balleine BW, Delgado MR, Hikosaka O (2007). The role of the dorsal striatum in reward and decision-making. J Neurosci 27: 8161-8165.

Bierczynska-Krzysik A, Pradeep John JP, Silberring J, Kotlinska J, Dylag T, Cabatic M et al (2006). Proteomic analysis of rat cerebral cortex, hippocampus and striatum after exposure to morphine. Int J Mol Med 18: 775-784.

Blednov YA, Harris RA (2009). Deletion of vanilloid receptor (TRPV1) in mice alters behavioral effects of ethanol. Neuropharmacology 56: 814-820.

Cavanaugh DJ, Chesler AT, Jackson AC, Sigal YM, Yamanaka H, Grant R et al (2011). Trpv1 reporter mice reveal highly restricted brain distribution and functional expression in arteriolar smooth muscle cells. J Neurosci 31: 5067-5077.

Chen Y, Geis C, Sommer C (2008). Activation of TRPV1 contributes to morphine tolerance: involvement of the mitogen-activated protein kinase signaling pathway. J Neurosci 28: 5836-5845.

Cristino L, de Petrocellis L, Pryce G, Baker D, Guglielmotti V, Di Marzo V (2006). Immunohistochemical localization of cannabinoid 
type 1 and vanilloid transient receptor potential vanilloid type 1 receptors in the mouse brain. Neuroscience 139: 1405-1415.

Fattore L, Vigano D, Fadda P, Rubino T, Fratta W, Parolaro D (2007). Bidirectional regulation of mu-opioid and CB1-cannabinoid receptor in rats self-administering heroin or WIN 55,212-2. Eur J Neurosci 25: 2191-2200.

Gerdjikov TV, Ross GM, Beninger RJ (2004). Place preference induced by nucleus accumbens amphetamine is impaired by antagonists of ERK or p38 MAP kinases in rats. Behav Neurosci 118: $740-750$.

Goswami C, Rademacher N, Smalla KH, Kalscheuer V, Ropers HH, Gundelfinger ED et al (2010). TRPV1 acts as a synaptic protein and regulates vesicle recycling. J Cell Sci 123: 2045-2057.

Grueter BA, Brasnjo G, Malenka RC (2010). Postsynaptic TRPV1 triggers cell type-specific long-term depression in the nucleus accumbens. Nat Neurosci 13: 1519-1525.

Hayase T (2011). Differential effects of TRPV1 receptor ligands against nicotine-induced depression-like behaviors. BMC Pharmacol 11: 11.

Kasckow JW, Mulchahey JJ, Geracioti TD Jr. (2004). Effects of the vanilloid agonist olvanil and antagonist capsazepine on rat behaviors. Prog Neuropsychopharmacol Biol Psychiatry 28: 291-295.

Kauer JA, Gibson HE (2009). Hot flash: TRPV channels in the brain. Trends Neurosci 32: 215-224.

Kelley AE, Holahan MR (1997). Enhanced reward-related responding following cholera toxin infusion into the nucleus accumbens. Synapse 26: 46-54.

Kim SY, Chudapongse N, Lee SM, Levin MC, Oh JT, Park HJ et al (2005). Proteomic analysis of phosphotyrosyl proteins in morphine-dependent rat brains. Brain Res Mol Brain Res 133: $58-70$.

Koob GF, Volkow ND (2010). Neurocircuitry of addiction. Neuropsychopharmacology 35: 217-238.

Lane-Ladd SB, Pineda J, Boundy VA, Pfeuffer T, Krupinski J, Aghajanian GK et al (1997). CREB (cAMP response elementbinding protein) in the locus coeruleus: biochemical, physiological, and behavioral evidence for a role in opiate dependence. J Neurosci 17: 7890-7901.

Li KW, Jimenez CR, van der Schors RC, Hornshaw MP, Schoffelmeer AN, Smit AB (2006a). Intermittent administration of morphine alters protein expression in rat nucleus accumbens. Proteomics 6: 2003-2008.

Li S, Lee ML, Bruchas MR, Chan GC, Storm DR, Chavkin C (2006b). Calmodulin-stimulated adenylyl cyclase gene deletion affects morphine responses. Mol Pharmacol 70: 1742-1749.

Maccarrone M, Rossi S, Bari M, De Chiara V, Fezza F, Musella A et al (2008). Anandamide inhibits metabolism and physiological actions of 2-arachidonoylglycerol in the striatum. Nat Neurosci 11: 152-159.

Marsch R, Foeller E, Rammes G, Bunck M, Kossl M, Holsboer F et al (2007). Reduced anxiety, conditioned fear, and hippocampal long-term potentiation in transient receptor potential vanilloid type 1 receptor-deficient mice. J Neurosci 27: 832-839.
Meffert MK, Baltimore D (2005). Physiological functions for brain NF-kappaB. Trends Neurosci 28: 37-43.

Nestler EJ, Aghajanian GK (1997). Molecular and cellular basis of addiction. Science 278: 58-63.

Nguyen TL, Nam YS, Lee SY, Kim HC, Jang CG (2010). Effects of capsazepine, a transient receptor potential vanilloid type 1 antagonist, on morphine-induced antinociception, tolerance, and dependence in mice. Br J Anaesth 105: 668-674.

Nielsen MD, Chan GC, Poser SW, Storm DR (1996). Differential regulation of type I and type VIII $\mathrm{Ca} 2+$-stimulated adenylyl cyclases by Gi-coupled receptors in vivo. J Biol Chem 271: 33308-33316.

Paxinos G, Franklin KBJ (2004). The Mouse Brain in Stereotaxic Coordinates, Compact. 2nd edn. Elsevier Academic Press: Amsterdam; Boston.

Schmitzer-Torbert N, Redish AD (2004). Neuronal activity in the rodent dorsal striatum in sequential navigation: separation of spatial and reward responses on the multiple $\mathrm{T}$ task. $J$ Neurophysiol 91: 2259-2272.

Song YJ, Jen KY, Soni V, Kieff E, Cahir-McFarland E (2006). IL-1 receptor-associated kinase 1 is critical for latent membrane protein 1-induced p65/RelA serine 536 phosphorylation and NFkappaB activation. Proc Natl Acad Sci USA 103: 2689-2694.

Starowicz K, Cristino L, Di Marzo V (2008). TRPV1 receptors in the central nervous system: potential for previously unforeseen therapeutic applications. Curr Pharm Des 14: 42-54.

Suto N, Wise RA, Vezina P (2011). Dorsal as well as ventral striatal lesions affect levels of intravenous cocaine and morphine selfadministration in rats. Neurosci Lett 493: 29-32.

Terwilliger RZ, Beitner-Johnson D, Sevarino KA, Crain SM, Nestler EJ (1991). A general role for adaptations in G-proteins and the cyclic AMP system in mediating the chronic actions of morphine and cocaine on neuronal function. Brain Res 548: 100-110.

Tominaga M, Caterina MJ, Malmberg AB, Rosen TA, Gilbert H, Skinner K et al (1998). The cloned capsaicin receptor integrates multiple pain-producing stimuli. Neuron 21: 531-543.

Toth A, Boczan J, Kedei N, Lizanecz E, Bagi Z, Papp Z et al (2005). Expression and distribution of vanilloid receptor 1 (TRPV1) in the adult rat brain. Brain Res Mol Brain Res 135: 162-168.

Vanderschuren LJ, Di Ciano P, Everitt BJ (2005). Involvement of the dorsal striatum in cue-controlled cocaine seeking. J Neurosci 25: 8665-8670.

Vetter I, Wyse BD, Monteith GR, Roberts-Thomson SJ, Cabot PJ (2006). The mu opioid agonist morphine modulates potentiation of capsaicin-evoked TRPV1 responses through a cyclic AMPdependent protein kinase A pathway. Mol Pain 2: 22.

Yang J, Yu J, Jia X, Zhu W, Zhao L, Li S et al (2011). Inhibition of nuclear factor-kappaB impairs reconsolidation of morphine reward memory in rats. Behav Brain Res 216: 592-596.

Zhang X, Cui Y, Jing J, Xin W, Liu X (2011). Involvement of p38/NF-kappaB signaling pathway in the nucleus accumbens in the rewarding effects of morphine in rats. Behav Brain Res 218: 184-189.

Supplementary Information accompanies the paper on the Neuropsychopharmacology website (http://www.nature.com/npp) 